\title{
Effect of a daily dose of Lactobacillus brevis CD2 lozenges in high caries risk schoolchildren
}

\author{
Guglielmo Campus • Fabio Cocco • Giovanna Carta • \\ Maria Grazia Cagetti • Charlotte Simark-Mattson • \\ Laura Strohmenger • Peter Lingström
}

Received: 29 January 2013 / Accepted: 8 April 2013 /Published online: 5 May 2013

(C) The Author(s) 2013. This article is published with open access at Springerlink.com

\begin{abstract}
Objectives A double-blind, randomised, placebo-controlled clinical trial was performed to validate the hypothesis that the use of lozenges containing Lactobacillus brevis CD2 (Inersan ${ }^{\circledR}, \mathrm{CD}$ Investments srl) may reduce plaque $\mathrm{pH}$, salivary mutans streptococci (ms) and bleeding on probing, during a 6week period, in a sample of high caries risk schoolchildren. Methods A total of 191 children (aged 6-8 years), presenting two to three carious lesions and a salivary ms concentration of $\geq 10^{5} \mathrm{CFU} / \mathrm{ml}$, were enrolled and divided into two groups, an $L$. brevis $\mathrm{CD} 2$ lozenge group and a no L. brevis lozenge group, and examined at baseline $\left(\mathrm{t}_{0}\right)$, after 3 weeks $\left(\mathrm{t}_{1}\right)$, after 6 weeks of lozenge use $\left(\mathrm{t}_{2}\right)$ and 2 weeks after the cessation of lozenge use $\left(t_{3}\right)$. Plaque $\mathrm{pH}$ was assessed using the microtouch technique following a sucrose challenge. The area under the curve $\left(\mathrm{AUC}_{5.7}\right.$ and $\left.\mathrm{AUC}_{6.2}\right)$ was recorded. Salivary ms were counted, and bleeding on probing was assessed.
\end{abstract}

G. Campus $(\bowtie) \cdot$ G. Carta

Department of Surgery, Microsurgery and Medical

Sciences, Dental School, University of Sassari,

Viale San Pietro 43/C, I-07100 Sassari, Italy

e-mail: gcampus@uniss.it

G. Campus • F. Cocco • M. G. Cagetti $\cdot$ L. Strohmenger $\cdot$

P. Lingström

WHO Collaborating Centre of Milan for Epidemiology

and Community Dentistry, Milan, Italy

F. Cocco

Department of Chemistry and Pharmacy,

University of Sassari, Sassari, Italy

C. Simark-Mattson $\cdot$ P. Lingström

Department of Cariology, Institute of Odontology,

The Sahlgrenska Academy, University of Gothenburg,

Gothenburg, Sweden
Results At $\mathrm{t}_{0}$, the plaque-pH and $\mathrm{ms}$ concentration values were similar in both groups. Mean areas $\left(\mathrm{AUC}_{5.7}\right.$ and $\mathrm{AUC}_{6.2}$ ) were significantly greater in the control group at $t_{1}$, $\mathrm{t}_{2}$ and $\mathrm{t}_{3}$. L. brevis CD2 lozenges significantly reduced salivary ms concentrations and bleeding. The subjects from the test group showed a statistically significant decrease $(p=0.01)$ in salivary ms concentration. At $t_{2}$, a statistically significantly lower bleeding value was recorded in the test group compared with the control group $(p=0.02)$.

Conclusions Six weeks' use of lozenges containing L. brevis CD2 had a beneficial effect on some important variables related to oral health, including a reduction in plaque acidogenicity, salivary ms and bleeding on probing. (Trial Registration Number NCT01601145 08/21/2012)

Keywords Probiotic $\cdot$ Lactobacillus brevis CD2 - Caries · Plaque $\mathrm{pH} \cdot$ Salivary mutans streptococci $\cdot$ Children

\section{Introduction}

Dental caries is the interaction over time between cariogenic microflora, a diet rich in fermentable carbohydrates and host factors, including saliva secretion rate and buffering capacity [1]. Caries is still one of the most common diseases among children, although a declining prevalence trend has been recorded in western countries [2-7]. Preventive programmes to control caries risk factors, focusing on dietary modification and enhancing host resistance through the use of fluoride and sealants, are recommended [8]. However, in recent years, a complete eradication of caries-associated micro-organisms has proved to be difficult and almost impossible but quite unwise [9]. 
Recent studies have shed a new light on the potential for using probiotics for the prevention of oral diseases, i.e. a shift in the microbial population towards a pathogen-associated population, which is central to the development of the major oral diseases (caries and periodontal disease). Preliminary data on probiotics obtained by various research groups $[10,11]$ have been encouraging, but further randomised clinical studies are still required clearly to establish their potential for preventing and treating oral infections. These studies will enable the identification of the probiotics that are best suited for oral use, as well as the vehicles that are the most appropriate for administration: food products (cheese, milk, yogurt) or supplements (chewing gum, lozenges).

The main goal for the use of probiotics in caries prevention is the inhibition of the proliferation of cariogenic bacteria (mainly Streptococcus mutans) and the reduction of their adherence to the tooth surfaces. In vitro studies $[12,13]$ have demonstrated the capacity of probiotics to inhibit Streptococcus sobrinus. The inhibition of $S$. mutans growth and biofilm formation by several probiotic strains like Lactobacillus plantarum DSM 9843, Lactobacillus reuteri PTA 5289, L. reuteri ATCC 55730 and so on has been reported $[11,14,15]$. A significant decrease in salivary $S$. mutans concentration was observed following the consumption of probiotic ice cream containing Bifidobacterium lactis $\mathrm{Bb}-12$ or chewing gum containing $L$. reuteri $[10,11]$.

The hypothesis of this study is that the use of lozenges containing Lactobacillus brevis $\mathrm{CD} 2$ may reduce plaque $\mathrm{pH}$, salivary mutans streptococci (ms) concentration and bleeding on probing in a sample of high caries risk schoolchildren. To validate this hypothesis, a randomised clinical trial was designed and performed.

\section{Materials and methods}

Study design and registration of the study

The study was designed as a randomised clinical trial, approved by the Ethics Committee at the University of Sassari, Italy (no. 108SS/2012), and registered at www.clinicaltrials.gov (NCT NCT01601145). The study was carried out in Sassari, where the total number of children aged 6-8 years in 2011 was 3,258. Power analysis was performed using $G^{*}$ Power 3.1.3 for Apple using ANOVA for repeated measures and, taking account of a disease prevalence of 0.51 with an effect size of 0.06 and an error probability of 0.05 , the number of subjects in each group was set at 78 , with an actual power of 0.95 . The sample size was calculated on the basis of previous studies of caries prevalence $[3,4]$. It was increased by $15 \%$ to safeguard the estimates at an optimal level of precision (5\%) against the possible effect of disease reduction compared with previous studies and the number of non-responders. The total theoretical sample size was set at 180 .

\section{Preliminary screening}

Screening was carried out from November 2011 to January 2012 to select children who presented two to three manifest carious lesions in the permanent and/or primary dentition and a salivary mutans streptococci (ms) concentration of $\geq 10^{5} \mathrm{CFU} / \mathrm{mL}$. Carious lesions were diagnosed when there was a cavity at dentinal level $\left(\mathrm{D}_{3}\right)$. Subjects with a history of systemic antibiotic, topical fluoride (except for toothpaste) or chlorhexidine treatment within 30 days before baseline were excluded.

Schoolchildren were recruited using systematic cluster sampling; each class was identified as a cluster and compiled into a list. The first cluster was randomly chosen, while the others were selected at the systematic interval of three classes. In all, 564 children were recruited for the preliminary screening.

An information leaflet, explaining the aim of the study and requesting their child's participation with signed consent, was given to parents or guardians. Only children with parents' signed consent were called for examination (534 subjects). The clinical examination and the saliva sampling were performed during the school day; 526 children showed up at the time scheduled for the examination, 208 met the inclusion criteria and were enrolled in the study. The flow chart of the study design is shown in Fig. 1.

A second leaflet explaining the aim of the clinical trial and requiring the child's participation was mailed to all parents/guardians of the 208 children. The investigation had a randomised, placebo-controlled study design, including a plaque acidogenicity evaluation, a microbiological evaluation and bleeding on probing, with an experimental period of 8 weeks.

The clinical trial was carried out from January to July 2012. The study design included a first examination (saliva sample, plaque-pH evaluation and periodontal probing) at baseline $\left(\mathrm{t}_{0}\right)$, a second after 3 weeks $\left(\mathrm{t}_{1}\right)$, a third after 6 weeks $\left(t_{2}\right)$ of lozenge use and a final examination 2 weeks after the end of lozenge use $\left(t_{3} ;\right.$ Fig. 1). One week before the start of the experiment, all the subjects began to use a $1,400-\mu \mathrm{g} / \mathrm{g}$ AmF toothpaste (Gaba-Colgate, Rome), for daily oral hygiene. A soft toothbrush was likewise provided, and they were asked to avoid any other oral hygiene adjuvant.

Moreover, the children received a patient diary, which informed them that the use of any fluoride-containing oral hygiene products (other than the toothpaste handed to the participants), any fluoride-containing mineral water or black tea, fish meals and commercial probiotic products was not allowed during the study.

Two groups of children were created: (1) a test group, using non-sucrose lozenges containing $L$. brevis $\mathrm{CD} 2$, and 
November 2011 - January 2012

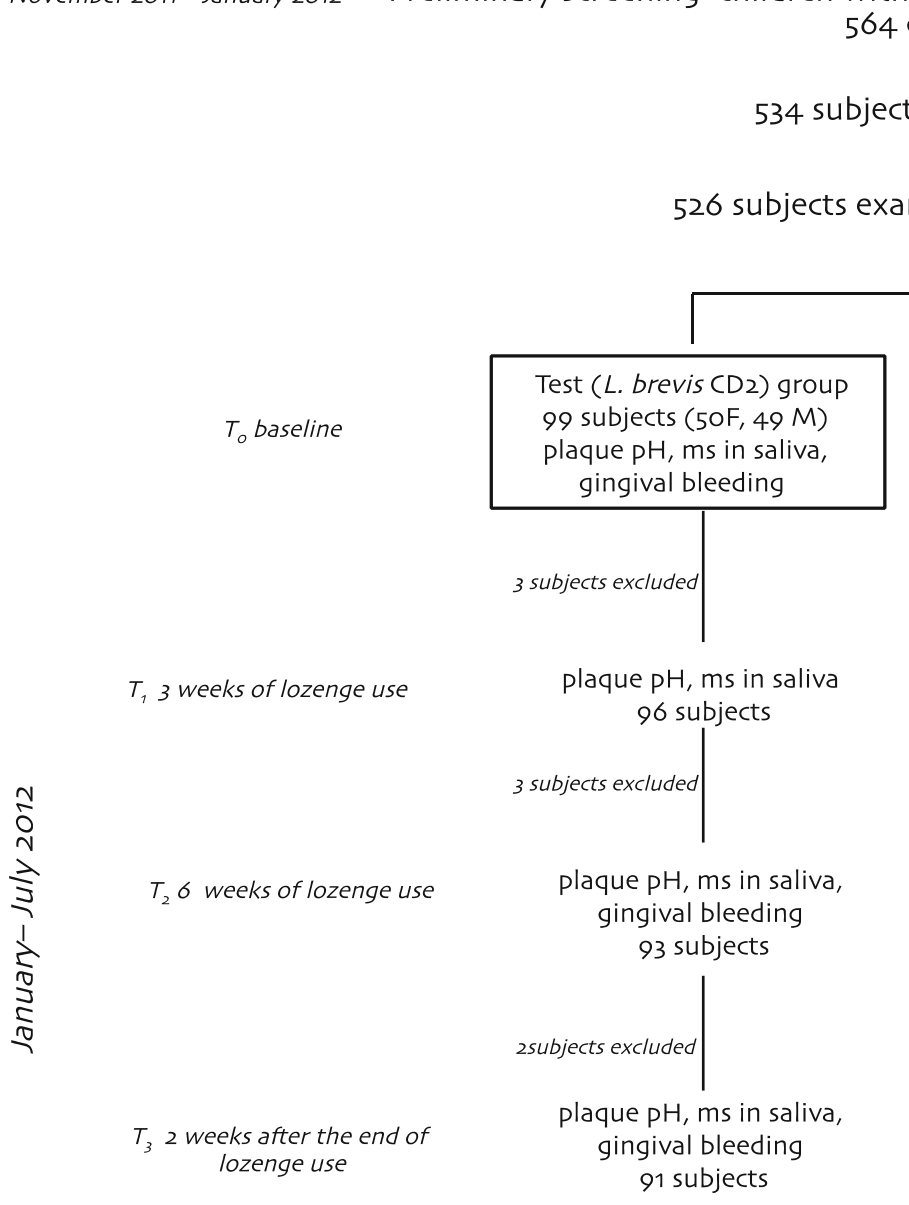

with 2-3 manifest caries lesions and $\mathrm{ms}>10^{5} \mathrm{CFU} / \mathrm{ml}$ in saliva 64 children (aged 6-8 years)

1

parents' signed consent

8 fulfilled inclusion criteria

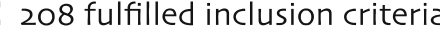

subjects did not participate

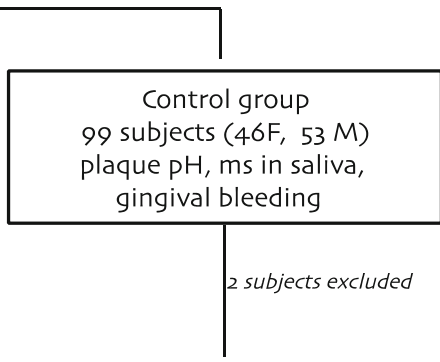

plaque $\mathrm{pH}$, ms in saliva, 97 subjects

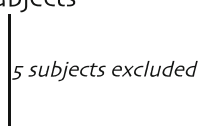

plaque $\mathrm{pH}$, ms in saliva, gingival bleeding 92 subjects

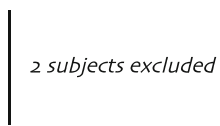

plaque $\mathrm{pH}$, ms in saliva, gingival bleeding 90 subjects

Fig. 1 Flow chart of the study design

(2) a control group, using non-sucrose lozenges with no active ingredient. Randomisation was carried out on an individual basis by GC and FC using Excel $^{\circledR} 2010$ for Mac. Ten subjects were absent at the start of the experiment, so the final study sample was 198 . At the $t_{1}$ interim evaluation, five children were excluded as they did not return the empty lozenge bottle (three from the test group and two from the control group), at $\mathrm{t}_{2}$ more children were excluded, three from the test group and five from the control group (four children had received systemic antibiotics therapy and four did not return the empty lozenge bottle), and, at $t_{3}$, four children refused to complete the experiment (two from the test group and two from the control group). As a result, 181 children concluded the 8-week experimental period: 91 in the test group and 90 in the control group.

Treatment and sample collection

The L. brevis CD2 lozenges (Inersan ${ }^{\circledR}, \mathrm{CD}$ Investments srl, Rome, Italy) contain 2,000,000,000 colonies of L. brevis CD2, sweeteners (mannitol, aspartame, fructose), anti- caking agents (talc, silicon dioxide, magnesium stearate) and banana flavouring. The lozenges for the control group contained exactly the same ingredients, except for the $L$. brevis CD2. The two lozenges were identical in weight (1 g), form, colour and packing. They were produced and supplied by CD Investments Srl (Rome, Italy) and coded as either "green" or "red". The code was sealed by an independent monitor and was not broken until the statistical analysis was finalised. Each subject took two lozenges a day, one in the morning and one in the evening, for the whole experimental period.

The parents/guardians were asked to make no changes to the dietary and oral hygiene habits of their children. Toothbrushing was not allowed for at least $1 \mathrm{~h}$ after the use of the lozenges.

In order to evaluate the administration of the products at school and home, teachers and parents were given lozenges necessary for 2 weeks at a time and were asked to return the empty bottles when receiving those necessary for the following period. This procedure was repeated throughout the whole experimental period. The compliance and any observed side effects of the administration of the products 
were assessed by means of a questionnaire administered to the participants' parents at $t_{2}$.

\section{Plaque-pH evaluation}

The children refrained from eating/drinking $1 \mathrm{~h}$ before plaque$\mathrm{pH}$ evaluation. No toothbrushing or other tooth-cleaning methods were allowed on the morning of the measurement day. Plaque acidogenicity was assessed using the microtouch technique after a sucrose challenge. Evaluations of $\mathrm{pH}$ were carried out at two proximal sites (between the deciduous molars) on the left and right sides of the upper jaw. The $\mathrm{pH}$ of each site was measured in triplicate at six different time points: before the sucrose rinse and 2, 5, 10, 15 and $20 \mathrm{~min}$ after a 1-min rinse with $10 \mathrm{ml}$ of $10 \%$ sucrose, using active movements. An iridium touch microelectrode, diameter $0.1 \mathrm{~mm}$ (Beetrode NMPH-1, World Precision Instruments, Sarasota, FL, USA) [16], with a porous glass reference electrode, was used (MERE 1, WPI, Sarasota, FL, USA). Before each session of $\mathrm{pH}$ evaluation, the electrode was calibrated using buffer solution at $\mathrm{pH} 7.00$ and 4.00 [17].

\section{Microbiological analyses}

Non-stimulated whole saliva was collected for $150 \mathrm{~s}$ in sterile vials (Nunc, Kamstrup, Denmark). The samples were processed within 45 min of collection at the Department of Microbiology (University of Sassari). The samples were serially diluted in sterile PBS (Sigma Chemicals, St. Louis, MO, USA). Aliquots of $5 \mu \mathrm{l}$ were inoculated on Mitis-Salivarius Bacitracin Agar [18] for the evaluation of ms. The plates were incubated in a $5 \% \mathrm{CO}_{2}$ environment at $37^{\circ} \mathrm{C}$ for $72 \mathrm{~h}$, and the colony forming units (CFU) were identified by morphology, size and colour and counted in a stereomicroscope; the ms concentration in saliva was expressed as $\log _{10}$ CFU per milliliter.

\section{Bleeding on probing}

Bleeding on probing was recorded dichotomously as bleeding or not, $30 \mathrm{~s}$ after the gentle manipulation of the tissue at the depth of the gingival sulcus by a probe. Bleeding on probing was checked at $t_{0}, t_{2}$ and $t_{3}$ by one calibrated examiner (GC) before the plaque-pH evaluation. Intraexaminer reliability was assessed before the start of the study on 20 subjects. Cohen's kappa value for the bleeding score was 0.81 . Examinations were carried out under standardised conditions, using optimal artificial lighting, a plain mirror and a WHO-CPI probe.

Statistical methods

The mean $\mathrm{pH}$ of the $\mathrm{pH}$ readings for each individual site was calculated. The mean for the two sites at the different time points was calculated, as well as minimum $\mathrm{pH}$ and maximum $\mathrm{pH}$ fall. The area between reference $\mathrm{pH}\left(\mathrm{AUC}_{5.7}\right.$ and $\mathrm{AUC}_{6.2}$ ) and the $\mathrm{pH}$ curve was calculated using "Plaque$\mathrm{pH}$ " software [19]. The salivary ms concentrations were transformed to $\log _{10}$ values to normalise the data, and the mean and standard error (SE) was calculated for each group and time point. Data were analysed for statistically significant differences using repeated one-way and two-way measures analysis of variance (ANOVA). At $t_{2}$, the subjects were divided according to salivary $\mathrm{ms}$ concentration $\left(<10^{5}\right.$ and $\geq 10^{5}$ ), and the areas under the plaque-pH curve $\left(\mathrm{AUC}_{5.7}\right.$ and $\mathrm{AUC}_{6.2}$ ) for the two groups were compared in order to evaluate the possible relationship between salivary ms concentration and plaque $\mathrm{pH}$. The difference between $\mathrm{t}_{0}$ and $t_{2}$ in the AUC and in the salivary concentration of ms was also calculated for each subject, and a linear regression analysis was computed.

The number of bleeding sites was added together, and the result was expressed as a percentage of the total number of surfaces. Adjustment of type I error due to multiple testing is not considered necessary due to the a priori ordering of the hypotheses. Hypothesis testing has to be stopped if a null hypothesis cannot be rejected at the $5 \%$ error level $\alpha$. This procedure maintains a constant global level of $\alpha=5 \%$. All the analyses were carried out using Stata SE software 10.0. A $p$ value of $<0.05$ was considered statistically significant.

\section{Results}

No adverse effects were reported by the children in either group. A total of 181 children completed the experimental period (Fig. 1): 91 subjects in the test group and 90 in the control group. There were 16 drop-out subjects $(8.1 \%)$ during the 2-month period. The mean number of $\mathrm{D}_{3}$ lesions in all dentition (deciduous/permanent) was 2.61 in the test group and 2.54 in the control group $(p=0.36)$. At $\mathrm{t}_{0}$, plaque $\mathrm{pH}$ and the salivary $\mathrm{ms}$ concentration were similar in both groups, with no statistically significant differences for the two variables observed $(p=0.18$ and $p=0.48$, respectively).

Table 1 shows the mean $\pm \mathrm{SE}$ for $\mathrm{AUC}_{5.7}$ and $\mathrm{AUC}_{6.2}$ during the trial. At baseline, the values for $\mathrm{AUC}_{5.7}$ and $\mathrm{AUC}_{6.2}$ were similar in the two groups $(p=0.60$ and $p=$ 0.15 , respectively). Mean areas $\left(\mathrm{AUC}_{5.7}\right.$ and $\left.\mathrm{AUC}_{6.2}\right)$ were statistically significantly different at the following time points $\left(t_{1}, t_{2}\right.$ and $\left.t_{3}\right)$, with the largest difference at $t_{2}$. The differences were statistically dissimilar in each group when it came to time intervals ( $p<0.01$ in the $L$. brevis $\mathrm{CD} 2$ group and 0.03 in the control group for $\mathrm{AUC}_{62}$ ). The minimum $\mathrm{pH}$ showed small variations among the four time points for the test group, whereas in the control group, a decrease was 
Table $1 \mathrm{AUC}_{5.7}$ and $\mathrm{AUC}_{6.2}$ (mean $\pm \mathrm{SE}$ ) during the experimental period in the two groups of children using lozenges with $L$. brevis $\mathrm{CD} 2$ (test group) and lozenges without probiotic bacteria (control group)

\begin{tabular}{|c|c|c|c|c|c|c|}
\hline \multirow[t]{2}{*}{ Time } & \multicolumn{3}{|c|}{$\mathrm{AUC}_{5.7}(\mathrm{pH} \times \min )$} & \multicolumn{3}{|c|}{$\mathrm{AUC}_{6.2}(\mathrm{pH} \times \min )$} \\
\hline & Test group & Control group & $\begin{array}{l}p \text { value } \\
\text { (one-way ANOVA) }\end{array}$ & Test group & Control group & $\begin{array}{l}p \text { value } \\
\text { (one-way ANOVA) }\end{array}$ \\
\hline $\mathrm{t}_{0}$ (baseline) & $11.3 \pm 0.5$ & $11.1 \pm 0.4$ & 0.60 & $22.0 \pm 0.8$ & $21.1 \pm 0.7$ & 0.15 \\
\hline $\mathrm{t}_{1}$ (after 3 weeks' lozenge use) & $9.1 \pm 0.3$ & $11.8 \pm 0.6$ & 0.02 & $17.6 \pm 0.8$ & $20.8 \pm 0.4$ & 0.03 \\
\hline$t_{2}$ (after 6 weeks' lozenge use) & $7.2 \pm 0.4$ & $11.2 \pm 0.7$ & $<0.01$ & $14.7 \pm 0.2$ & $20.9 \pm 0.8$ & $<0.01$ \\
\hline $\begin{array}{l}t_{3}(2 \text { weeks after the end of } \\
\text { lozenge use })\end{array}$ & $10.4 \pm 0.2$ & $12.0 \pm 0.2$ & 0.03 & $20.4 \pm 0.8$ & $21.2 \pm 0.5$ & 0.12 \\
\hline$p$ value (one-way ANOVA) & $<0.01$ & 0.14 & & $<0.01$ & 0.03 & \\
\hline
\end{tabular}

detected between $\mathrm{t}_{0}$ and $\mathrm{t}_{2} ; p$ values were statistically significant at the $t_{1}$ and $t_{2}$ inter-group comparison. The intergroup comparison of the maximum $\mathrm{pH}$ fall was statistically significant at $\mathrm{t}_{1}, \mathrm{t}_{2}$ and $\mathrm{t}_{3}, p=0.01, p<0.01$ and $p=0.04$, respectively (data not shown).

Similar results were noted for the salivary ms concentration (Table 2). The children from the test group showed a statistically significant decrease $(p=0.01)$ in the salivary $\mathrm{ms}$ concentration $\left(5.4\right.$ at $\mathrm{t}_{0}, 4.9$ at $\left.\mathrm{t}_{2}\right)$. In children from the control group, the salivary ms concentration remained at the same level during the whole experimental period. Areas under the curve at $t_{2}$ (Table 3 ) were statistically significantly smaller in children from the test group ( $p=0.01 \mathrm{AUC}_{5.7}$ and $p=0.03$ $\mathrm{AUC}_{6.2}$ ) in relation to the salivary $\mathrm{ms}$ concentration, if compared with the control group, for children at both ms concentrations $\left(>10^{5}, \leq 10^{5}\right)$.

The bleeding score at $\mathrm{t}_{0}$ was similar in the two groups (32.8\% in the control group and $33.4 \%$ in the test group), while, at $t_{2}$, a statistically significantly lower value was recorded in the test group compared with the control group $(p=0.02)$. At $t_{3}$, the difference in bleeding score was still statistically significant $(p=0.03)$, with a value of 24.4 [95\% confidence interval $(\mathrm{CI})=19.0-30.1$ ] in the test group and 28.6 (95\% CI, 23.5-33.8) in the control group (Fig. 2).

\section{Discussion}

The effect of $L$. brevis $\mathrm{CD} 2$, administered daily through lozenges at a frequency of two times/day, on plaque acidogenicity, ms concentration and gingival bleeding in a group of high caries risk children was evaluated. The main finding from this randomised clinical trial is that $L$. brevis $\mathrm{CD} 2$ lozenges were effective in reducing plaque acidogenicity and salivary ms concentrations. A reduction in the bleeding score was also observed in the test group. It has been documented that probiotics can act locally in the oral cavity through the biofilm and systemically by modifying the immune response [20].

A significant reduction in plaque acidogenicity was found after 6 weeks' use of the probiotic lozenges. The short-term consumption ( 2 weeks) of probiotic lactobacilli has not been found to influence plaque acidogenicity or ms levels in plaque [15]. One interesting observation was that the effect on plaque acidogenicity appeared to be reduced during the last 2 weeks of the experimental period, when no product was used. This indicates the importance of the continuous administration of probiotic products in order to achieve a lasting effect on different oral variables, as has previously been suggested [12]. Probiotic bacteria can survive and grow in the oral environment, although permanent colonisation is unlikely in an established oral biofilm [21, 22].
Table 2 Concentration of mutans streptococci $\left(\log _{10} \mathrm{CFU} /\right.$ $\mathrm{ml}$ saliva: mean $\pm \mathrm{SE}$ ) at $\mathrm{t}_{0}, \mathrm{t}_{1}, \mathrm{t}_{2}$ and $t_{3}$ in the two groups of children using lozenges with $L$. brevis CD2 (test group) and lozenges without probiotic bacteria (control group)

\begin{tabular}{llll}
\hline Time & Test group & Control group & $p$ value(one-way ANOVA) \\
\hline $\mathrm{t}_{0}$ (baseline) & $5.4 \pm 0.3$ & $5.4 \pm 0.2$ & 0.36 \\
$\mathrm{t}_{1}$ (after 3 weeks' lozenge use) & $5.2 \pm 0.5$ & $5.4 \pm 0.0$ & 0.04 \\
$\mathrm{t}_{2}$ (after 6 weeks' lozenge use) & $4.9 \pm 0.1$ & $5.4 \pm 0.4$ & 0.01 \\
$\mathrm{t}_{3}$ (2 weeks after the end of lozenge use) & $5.1 \pm 0.4$ & $5.4 \pm 0.4$ & 0.02 \\
$p$ value (one-way ANOVA) & 0.01 & 0.48 & \\
\hline
\end{tabular}


Table 3 Areas under the curve $\left(\mathrm{AUC}_{5.7}\right.$ and $\left.\mathrm{AUC}_{6.2}\right)$ in relation to salivary ms concentration $\left(\leq 10^{5}\right.$ and $\left.>10^{5}\right)$ at $\mathrm{t}_{2}$ for the two groups of children using lozenges with L. brevis CD2 (test group) and lozenges without probiotic bacteria (control group)

\begin{tabular}{|c|c|c|c|c|c|c|}
\hline & \multicolumn{3}{|l|}{$\mathrm{AUC}_{5.7}$} & \multicolumn{3}{|l|}{$\mathrm{AUC}_{6.2}$} \\
\hline & $\begin{array}{l}\mathrm{ms} \leq 10^{5} \\
\operatorname{mean} \pm \operatorname{SD}(n)\end{array}$ & $\begin{array}{l}\mathrm{ms}>10^{5} \\
\text { mean } \pm \mathrm{SD}(n)\end{array}$ & $\begin{array}{l}\text { p-value } \\
\text { (one-way ANOVA) }\end{array}$ & $\begin{array}{l}\mathrm{ms} \leq 10^{5} \\
\text { mean } \pm \mathrm{SD}(n)\end{array}$ & $\begin{array}{l}\mathrm{ms}>10^{5} \\
\text { mean } \pm \mathrm{SD}(n)\end{array}$ & $\begin{array}{l}p \text { value } \\
\text { (one-way ANOVA) }\end{array}$ \\
\hline Test group & $4.3 \pm 0.7(39)$ & $6.2 \pm 0.9(52)$ & 0.01 & $8.1 \pm 0.4(39)$ & $9.3 \pm 0.4(52)$ & 0.03 \\
\hline Control group & $8.0 \pm 0.2(13)$ & $9.1 \pm 0.8$ (77) & 0.12 & $13.3 \pm 0.4(13)$ & $14.8 \pm 0.2(77)$ & 0.04 \\
\hline$p$ value (one-way ANOVA) & $<0.01$ & 0.01 & & $<0.01$ & $<0.01$ & \\
\hline
\end{tabular}

$\operatorname{Mean} \pm \operatorname{SE}(N)$

Previous studies have suggested that the intake of various strains of the lactobacilli species may reduce the counts of salivary mutans streptococci in children, even if it is only for the observational period $[10,23,24]$. In the present study, a statistically significant reduction in the salivary ms counts was observed. One of the explanatory hypotheses is linked to the release of arginine deiminase by the probiotic in general [25] and by L. brevis CD2 in particular [26]. Arginine deiminase is an enzyme that is normally confined to the prokaryotic kingdom [27]. This enzyme is able to catalyse the conversion of arginine to citrulline and ammonia; as many bacteria can use arginine as their only source of energy for growth, an arginine deficiency can reduce bacterial proliferation [28].

The change in the concentration of $\mathrm{ms}$ in saliva may reflect a change in the plaque microflora as well. Otherwise, some other results would require more investigation. For instance, the very low maximum $\mathrm{pH}$ at $\mathrm{t}_{1}$ for the test group is not logical, and the same also holds true for the time of 10$20 \mathrm{~min}$ for $\mathrm{t}_{3}$ and the test group; this is the reason why the AUC increases. These are the reasons why the "minimum $\mathrm{pH}$ " and "maximum pH fall" are not $100 \%$ logical, when comparing the test and control groups. One hypothesis could be that people in the test group respond differently to the L. brevis

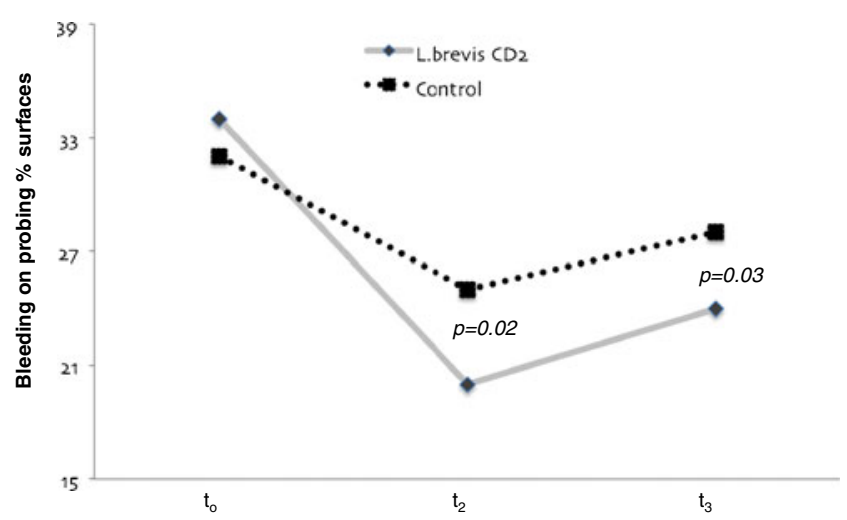

Fig. 2 Bleeding score (percentage) recorded at $t_{0}, t_{2}$ and $t_{3}$ in the two groups of children using lozenge with $L$. brevis $\mathrm{CD} 2$ respective lozenge without probiotic bacteria (control). One-way ANOVA
CD2. A high variability in the response to the effect of different probiotics has been described and, in a recent review, it was concluded that the same strain does not appear to be ideal for everyone [20].

A significant reduction in gingival bleeding was found after 6 weeks' use of the probiotic lozenges and 2 weeks after the cessation of use. The anti-inflammatory effects of $L$. brevis CD2 administered through lozenges in a group of patients with chronic periodontitis were studied [29]. One possible explanation for the beneficial anti-inflammatory effects of $L$. brevis $\mathrm{CD} 2$ could be its capacity to prevent the production of nitric oxide and, consequently, the release of PGE2 and the activation of MMPs induced by the nitric oxide.

To the authors' knowledge, this study is the first randomised clinical trial of the efficacy of probiotics in relation to plaque acidogenicity. Furthermore, no previous clinical trials have used the $L$. brevis $C D 2$ as probiotic strain. The findings are novel and fairly interesting, as the lozenge administration was well accepted by the children and the treatment proved to be effective and simple. In spite of these positive aspects, it is important to underline that these results were obtained in a, relatively speaking, shortterm period, and they had to be probably considered as temporary benefits. Further investigations are needed to evaluate a long-term effect on caries-related variables as well as the caries incidence which was not the outcome of this study. It is from the literature [30] well known that a long-term administration of probiotic is needed to gain health benefits. A strength of the present study is that also gingival health was monitored, which is an important feature of children oral health.

In conclusion, the 6-week administration of probiotic bacteria (L. brevis CD2) through lozenges is able to reduce same important variables related to oral health. A reduction of plaque $\mathrm{pH}$, salivary mutans streptococci concentration and bleeding on probing in a sample of high caries risk schoolchildren can concur to reduce caries risk and to increase gingival health. This study provides evidence in favour of the potential use of L. brevis CD2 as a new functional food. 
Acknowledgments The authors acknowledge the willingness of parents to provide consent for the participation of their children and teachers for administering the lozenges. This research received no specific grant from any funding agency in the public, commercial or not-for-profit sectors.

Conflict of interest The authors declare that they have no competing interests.

Open Access This article is distributed under the terms of the Creative Commons Attribution License which permits any use, distribution, and reproduction in any medium, provided the original author(s) and the source are credited.

\section{References}

1. Selwitz RH, Ismail AI, Pitts NB (2007) Dental caries. Lancet 369:51-59

2. Marthaler TM (2004) Changes in dental caries 1953-2003. Caries Res 38:173-181

3. Campus G, Solinas G, Cagetti MG, Senna A, Minelli L, Majori S, Montagna MT, Reali D, Castiglia P, Strohmenger L (2007) National pathfinder survey of 12-year-old children's oral health in Italy. Caries Res 41:512-517

4. Campus G, Solinas G, Strohmenger L, Cagetti MG, Senna A, Minelli L, Majori S, Montagna MT, Reali D, Castiglia P, Collaborating Study Group (2009) National pathfinder survey on children's oral health in Italy: pattern and severity of caries disease in 4-year-olds. Caries Res 43:155-162

5. Marja-Leena M, Paivi R, Sirkka J, Ansa O, Matti S (2008) Childhood caries is still in force: a 15-year follow-up. Acta Odontol Scand 66:189192

6. Lingström P, van Ruyven FO, van Houte J, Kent R (2000) The pH of dental plaque in its relation to early enamel caries and dental plaque flora in humans. J Dent Res 79:770-777

7. Cagetti MG, Campus G, Sale S, Cocco F, Strohmenger L, Lingström P (2011) Association between interdental plaque acidogenicity and caries risk at surface level: a cross sectional study in primary dentition. Int J Paediatr Dent 21:119-125

8. Petersen PE, Lennon MA (2004) Effective use of fluorides for the prevention of dental caries in the 21 st century: the WHO approach. Community Dent Oral Epidemiol 32:319-321

9. Zero DT (2006) Dentifrices, mouthwashes and remineralization/ caries arrestment strategies. BMC Oral Health 6:9

10. Caglar E, Kuscu OO, Selvi Kuvvetli S, Kavaloglu Cildir S, Sandalli N, Twetman S (2008) Short-term effect of ice-cream containing Bifidobacterium lactis $\mathrm{Bb}-12$ on the number of salivary mutans streptococci and lactobacilli. Acta Odontol Scand 66:154158

11. Caglar E, Kavaloglu SC, Kuscu OO, Sandalli N, Holgerson PL, Twetman S (2007) Effect of chewing gums containing xylitol or probiotic bacteria on salivary mutans streptococci and lactobacilli. Clin Oral Investig 11:425-429

12. Meurman JH, Stamatova I (2007) Probiotics: contributions to oral health. Oral Dis 13:443-451
13. Söderling EM, Marttinen AM, Haukioja AL (2011) Probiotic lactobacilli interfere with Streptococcus mutans biofilm formation in vitro. Curr Microbiol 62:618-622

14. Tanzer JM, Thompson A, Lang C, Cooper B, Hareng L, Gamer A et al (2010) Caries inhibition by and safety of Lactobacillus paracasei DSMZ16671. J Dent Res 89:921-926

15. Marttinen A, Haukioja A, Karjalainen S, Nylund L, Satokari R, Öhman C et al (2012) Short-term consumption of probiotic lactobacilli has no effect on acid production of supragingival plaque. Clin Oral Investig 16:797-803

16. Lingström P, Imfeld T, Birkhed D (1993) Comparison of three different methods for measurement of plaque-pH in humans after consumption of soft bread and potato chips. J Dent Res 72:865-870

17. Scheie AA, Fejerskov O, Lingström P, Birkhed D, Manji F (1992) Use of palladium touch microelectrodes under field conditions for in vivo assessment of dental plaque-pH in children. Caries Res 26:44-52

18. Gold O, Jordan KV, van Houte J (1973) A selective medium for Streptococcus mutans. Arch Oral Biol 18:1357-1364

19. Larsen MJ, Pearce EI (1997) A computer program for correlating dental plaque- $\mathrm{pH}$ values, $\mathrm{cH}+$, plaque titration, critical $\mathrm{pH}$, resting $\mathrm{pH}$ and the solubility of enamel apatite. Arch Oral Biol 42:475480

20. Twetman S, Keller MK (2012) Probiotics for caries prevention and control. Adv Dent Res 24:98-102

21. Haukioja A, Yli-Knuuttila H, Loimaranta V, Kari K, Ouwehand AC, Meurman JH et al (2006) Oral adhesion and survival of probiotic and other lactobacilli and bifidobacteria in vitro. Oral Microbiol Immunol 21:326-332

22. Yli-Knuuttila H, Snäll J, Kari K, Meurman JH (2006) Colonization of Lactobacillus rhamnosus GG in the oral cavity. Oral Microbiol Immunol 21:129-131

23. Näse L, Hatakka K, Savilahti E, Saxelin M, Pönkä A, Poussa T et al (2001) Effect of long-term consumption of a probiotic bacterium, Lactobacillus rhamnosus GG, in milk on dental caries and caries risk in children. Caries Res 35:412-420

24. Ahola AJ, Yli-Knuuttila H, Suomalainen T, Poussa T, Ahlström A, Meurman JH, Korpela R et al (2002) Short-term consumption of probiotic-containing cheese and its effect on dental caries risk factors. Arch Oral Biol 47:799-804

25. Wu J, Xie H (2010) Role of arginine deiminase of Streptococcus cristatus in Porphyromonas gingivalis colonization. Antimicrob Agents Chemother 54:4694-4698

26. Di Marzio L, Russo FP, D'Alò S, Biordi L, Ulisse S, Amicosante G, De Simone C, Cifone MG (2001) Apoptotic effects of selected strains of lactic acid bacteria on a human $\mathrm{T}$ leukemia cell line are associated with bacterial arginine deiminase and/or sphingomyelinase activities. Nutr Cancer 40:185-196

27. Cunin R, Glansdorff N, Pierard A, Stalon V (1968) Biosynthesis and metabolism of arginine in bacteria. Microbiol Rev 50:314-352

28. Marquis RE, Bender GR, Murray DR, Wong A (1987) Arginine deiminase system and bacterial adaptation to acid environments. Appl Environ Microbiol 53:198-200

29. Riccia DN, Bizzini F, Perilli MG, Polimeni A, Trinchieri V, Amicosante $\mathrm{G}$ et al (2007) Anti-inflammatory effects of Lactobacillus brevis (CD2) on periodontal disease. Oral Dis 13:376-385

30. Bonifait L, Chandad F, Grenier D (2009) Probiotics for oral health: myth or reality? J Can Dent Ass 75:585-590 